\title{
Charakterystyki statyczne nowoczesnych urządzeń do spawania łukowego
}

\section{Static characteristics of modern arc welding equipment}

\section{Streszczenie}

Analiza charakterystyk statycznych jest jedną z niewielu metod określania właściwości spawalniczych źródeł zasilających. Znajduje szerokie zastosowanie w odniesieniu do urządzeń transformatorowych i konwencjonalnych prostowników. Nowoczesne zasilacze inwertorowe z wbudowanymi układami regulacji, umożliwiającymi zaprogramowanie przebiegu charakterystyk statycznych, przeważnie $\mathrm{z}$ łatwością spełniają stawiane im, z punktu widzenia przebiegu procesu spawania, kryteria jakościowe. Jednak urządzenia te różnią się między sobą właściwościami użytkowymi, a określane w odpowiedni sposób charakterystyki statyczne nadal mogą być cennym źródłem informacji dotyczących właściwości technologicznych. W artykule przedstawiono wyniki badań charakterystyk statycznych urządzeń inwertorowych do spawania elektrodą otuloną oraz metodą MIG/MAG.

\section{Wstęp}

Opinia na temat właściwości użytkowych urządzeń spawalniczych może być różna. Z użyciem pewnych urządzeń pracuje się łatwiej, inne wymagają pewnej wprawy w posługiwaniu się nimi, jeszcze innymi trudno jest przeprowadzić skutecznie proces spawania. Również pod kątem jakości wykonywanego złącza zasilacze spawalnicze różnią się pomiędzy sobą. Pojawia się pytanie, jakie cechy i parametry zasilaczy spawalniczych wpływają na ich przydatność oraz komfort pracy. Jedną z niewielu metod określania właściwości urządzeń spawalniczych jest wyznaczanie ich zewnętrznych charakterystyk statycznych.

Mgr inż. Krzysztof Skrzyniecki, dr inż. Paweł Cegielski, dr hab. inż. Andrzej Kolasa, prof. PW, dr inż. Paweł Kołodziejczak - Politechnika Warszawska.
PN-EN 60974-1 określa wymagania bezpieczeństwa dotyczące konstrukcji i użytkowania spawalniczych źródeł energii do spawania łukowego i procesów pokrewnych. Wśród wielu parametrów definiuje także zewnętrzne charakterystyki statyczne jako zależność pomiędzy napięciem w stanie obciążenia i prądem spawania w umownych warunkach obciążenia (w energetycznym i cieplnym stanie ustalonym, gdzie źródło obciążone jest praktycznie bezindukcyjnym stałym obciążeniem rezystancyjnym o współczynniku mocy nie mniejszym niż 0,99 ) oraz definiuje ich główne typy:

- charakterystyka płaska (napięciowa), gdzie przy wzroście natężenia prądu napięcie maleje mniej niż o 7 V/100 A lub wzrasta mniej niż 10 V/100 A,

- charakterystyka opadająca (prądowa), gdzie przy wzroście natężenia prądu napięcie spada o ponad $7 \mathrm{~V} / 100 \mathrm{~A}$.

Wspomniana norma nie opisuje jednak metody ani warunków pomiarów. Jako badania wyrobu wymienione są jedynie pomiary: znamionowego napięcia 
w stanie jałowym, rezystancji izolacji, wytrzymałości dielektrycznej, pracy w stanie obciążenia. Pomiary pracy $\mathrm{w}$ stanie obciążenia obejmują badania prądu zwarcia w przypadku charakterystyki opadającej lub umownego prądu spawania w przypadku charakterystyki płaskiej. Brak jest natomiast definicji pomiaru charakterystyk statycznych oraz opisu metody jego przeprowadzenia.

Również specyfikacje techniczne urządzeń spawalniczych rzadko zawierają informacje dotyczące charakterystyki statycznej. Jeżeli są podawane, to w bardzo ogólnej, orientacyjnej formie.

Ocena właściwości zasilaczy łuku spawalniczego na podstawie charakterystyk statycznych znajduje zastosowanie w odniesieniu do urządzeń transformatorowych i konwencjonalnych prostowników. Nowoczesne zasilacze inwertorowe $\mathrm{z}$ wbudowanymi układami regulacji, umożliwiającymi zaprogramowanie przebiegu charakterystyk statycznych, przeważnie $\mathrm{z}$ łatwością spełniają stawiane im z punktu widzenia przebiegu procesu spawania kryteria jakościowe. Jednak urządzenia te różnią się między sobą właściwościami użytkowymi, a określane w odpowiedni sposób charakterystyki statyczne nadal mogą być cennym źródłem informacji dotyczących właściwości technologicznych. W dalszej części artykułu przedstawiono wyniki badań charakterystyk statycznych urządzeń inwertorowych do spawania elektrodą otuloną oraz metodą MIG/MAG.

Przedstawione wyniki prac badawczych i konstrukcyjnych otrzymano w ramach pracy naukowej finansowanej ze środków budżetowych na naukę w latach 2010-2013 jako projekt badawczy $[1,2,4,5]$.

\section{Pomiar charakterystyk statycznych}

Zewnętrzna charakterystyka statyczna jest wykresem zależności napięcia generowanego przez źródło spawalnicze w zależności od prądu płynącego w obwodzie. Określenie statyczna odnosi się do stałej długości łuku [3]. Aby wyeliminować wszelkie zaburzenia oraz nierównomierności związane z łukiem elektrycznym, pomiary charakterystyki statycznej wykonuje się z zastosowaniem sztucznego obciążenia. Jest nim element o znanej, najlepiej nastawnej oporności, włączony pomiędzy zaciski wyjściowe badanego źródła. Zmieniając płynnie wartość oporności, można uzyskać wykres charakterystyki statycznej.

Trudnością jest znalezienie odpowiedniego potencjometru zdolnego pracować przy prądach o wartości do kilkuset amperów oraz rozproszyć wytwarzaną przy tym energię bez jego uszkodzenia. Niekorzystne warunki mogą wystąpić ze względu na możliwość iskrzenia pomiędzy elementami nastawnymi potencjometru. Alternatywnym rozwiązaniem jest zastosowanie szeregu oporników o stałej oporności, jednak w tym przypadku nie jest możliwe uzyskanie charakterystyki o ciągłym przebiegu. Otrzymuje się wówczas

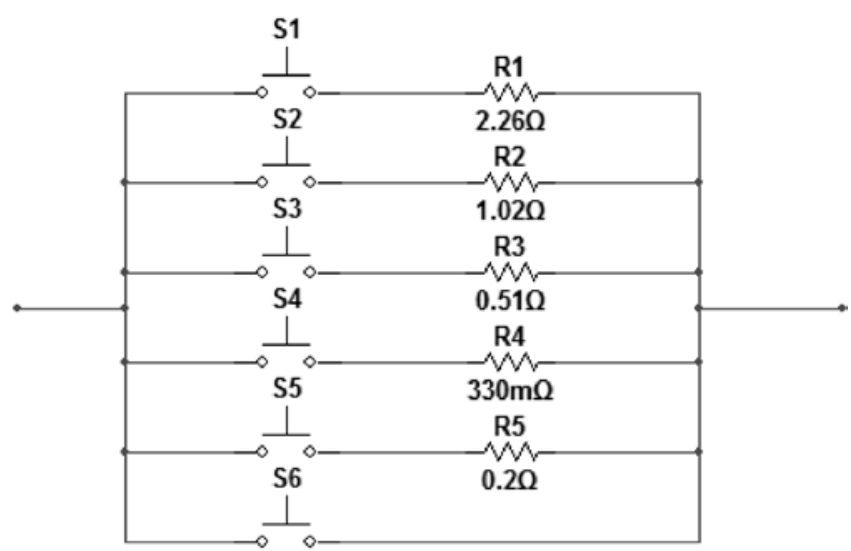

Rys. 1. Schemat obciążeń uzyskanych z połączenia oporników, zastosowany w badaniach

Fig. 1. Load diagram resulting from a combination of resistors, used in the study

skończoną liczbę punktów pomiarowych, która odpowiada liczbie dostępnych oporników. Ilość punktów można znacząco zwiększyć, stosując odpowiednie połączenia równoległe oporników (rys. 1), zgodnie ze wzorem:

$$
\frac{1}{R_{w}}=\frac{1}{R_{1}}+\frac{1}{R_{2}}+\cdots+\frac{1}{R_{n}}
$$

gdzie: $R_{w}$ - oporność wypadkowa stanowiąca obciążenie badanego urządzenie spawalniczego, $R_{1} \ldots R_{n}$ - dostępne oporności.

Niedogodnością zastosowania szeregu oporników jest konieczność przerwy w pomiarze na czas przełączenia kolejnej oporności. Aby ją wyeliminować, w omawianych badaniach funkcję łączników pełnią tranzystory IGBT sterowane przez komputerowy system pomiarowy $[1,2,5,6]$.

W konwencjonalnym podejściu urządzenie jest kolejno obciążane malejącą opornością (rys. 2), będącą połączeniem poszczególnych oporników. Pierwszy punkt obrazuje stan rozwarcia obwodu - nieskończenie

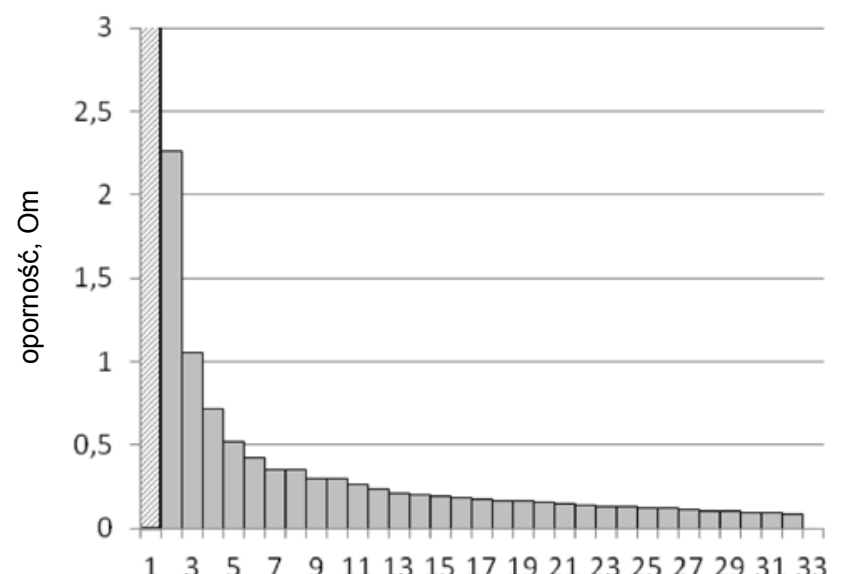

Rys. 2. Dostępne obciążenia, będące kombinacją wybranych oporników

Fig. 2. Available load, which is a combination of the separate resistors 


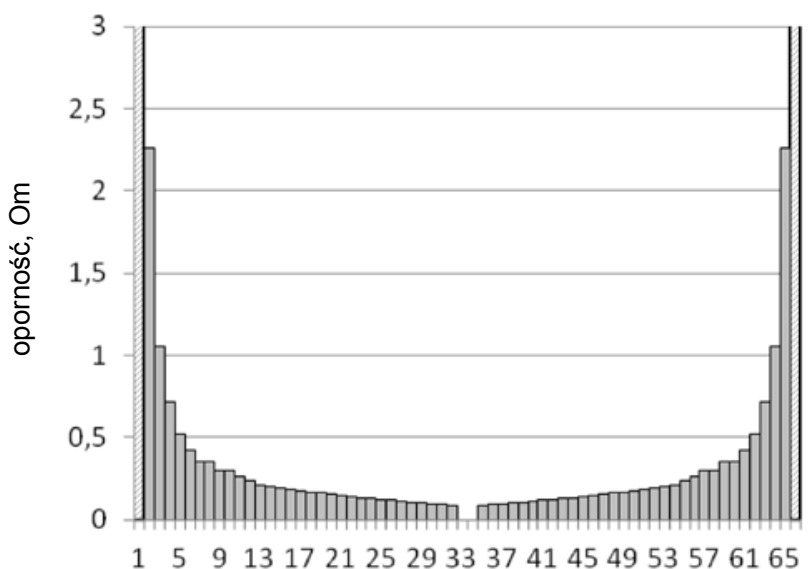

Rys. 3. Zmodyfikowany cykl obciążający, obejmujący malejącą oraz rosnącą rezystancję

Fig. 3. Modified loading cycle, including decreasing and increasing resistance

dużą rezystancję. Wartości dostępnych oporności wynikają z zastosowanego układu połączenia równoległego pięciu oporników oraz przewodu zwarciowego. Każdy z oporników może być dołączony do układu przez dołączenie odpowiadającego mu łącznika tranzystorowego IGBT. Odpowiedni dobór dołączonych oporności umożliwia uzyskanie oporności wypadkowej obciążającej badane źródło spawalnicze.

Można się spotkać z opinią, że współczesne urządzenia inwertorowe, dzięki komputerowym systemom sterowania, mogą generować dowolne przebiegi prądu i napięcia, a więc mają optymalne charakterystyki statyczne i nie ma potrzeby ich badania. Pogląd ten nie jest w pełni zasadny, gdyż właśnie takie systemy sterowania powodują różne reakcje źródeł zasilania w zależności od rodzaju obciążenia. Potwierdza to zmodyfikowany sposób pomiaru ich charakterystyk statycznych. Oprócz cyklu obciążania malejącymi opornościami wprowadzono dodatkowo cykl „powrotny", obejmujący stopniowo rosnące oporności (rys. 3). Pierwszy i ostatni punkt obrazują nieskończenie dużą oporność - stan rozwarcia. Badania niektórych urządzeń wykazały nawet znaczne rozbieżności pomiędzy charakterystykami uzyskanymi przy malejącym i rosnącym obciążeniu. Nie mogą one wynikać wyłącznie z nieliniowości elementów urządzenia, lecz są raczej wynikiem przełączania się trybów sterowania, w zależności od stanu pracy. Ma to istotne znaczenie dla przebiegu spawania, który łączy się z występowaniem zwarć oraz innych zaburzeń.

\section{Wyniki badań} lające:

Badaniami objęto cztery spawalnicze źródła zasi-

A inwertorowe $z$ prostym sterowaniem analogowym do spawania elektrodą otuloną,

B inwertorowe ze sterowaniem cyfrowym do spawania elektrodą otuloną,
C inwertorowe umożliwiające spawanie w trybie elektrody otulonej i metodą MIG/MAG,

D transformatorowe do spawania metodą MIG/MAG.

Przedstawione przebiegi prezentują zarejestrowane punkty, które zostały połączone liniami przerywanymi w celu lepszego zobrazowania ich kolejności, natomiast stany pomiędzy punktami nie są zdefiniowane (rys. $4 \div 8$ ). Ma to szczególne znaczenie w pobliżu punktu zwarcia. Na charakterystykach naniesiono strzałki obrazujące kierunek zmian obciążenia dla wybranej krzywej. Strzałka ciągła oznacza przebieg przy wzroście obciążenia, przerywana - przy spadku obciążenia (rys $4 \div 6$ ). Na rysunkach 7 i 8 krzywe te pokrywają się.

Urządzenia A oraz B wykazują stałoprądową charakterystykę w zakresie obszaru pracy, określonego przebiegiem umownego napięcia spawania $U=20+0,04$ I (rys. 4, 5), natomiast znacznie różnią się przebiegami przy zwarciu. W obu urządzeniach zastosowano układ ograniczający prąd zwarcia. Urządzenia przechodzą w ten tryb po wykryciu właściwej oporności obciążenia, a powracają do stanu pracy właściwej po wykryciu zbyt wysokiej oporności. Ma to szczególne znaczenie w przypadku spawania ręcznego elektrodą otuloną, podczas którego występują cykliczne

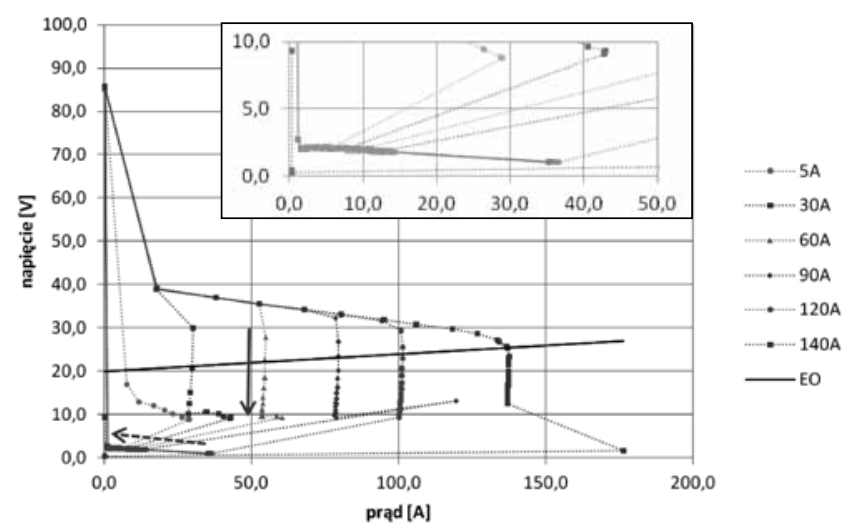

Rys. 4. Zbiór charakterystyk statycznych urządzenia A do spawania elektrodą otuloną z powiększonym wycinkiem w obszarze zwarcia Fig. 4. Static characteristics bunch of device A for MMA welding with an enhanced part in the circuit

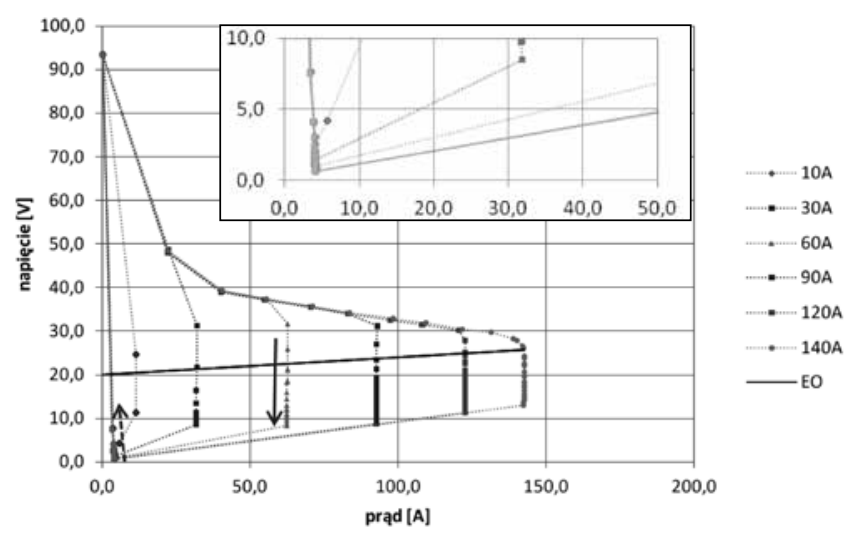

Rys. 5. Zbiór charakterystyk statycznych urządzenia B do spawania elektrodą otuloną z powiększonym wycinkiem w obszarze zwarcia Fig. 5. Static characteristics bunch of device B for MMA welding with an enhanced part in the circuit 
skracanie łuku oraz zwarcia. Ograniczenie prądu i napięcia ma na celu ułatwienie prowadzenia elektrody w spawaniu ręcznym.

W stanie zwarcia urządzenie takie przechodzi w tryb ograniczonego prądu oraz napięcia i pozostaje w nim aż do momentu rozwarcia obwodu. W trybie tym urządzenie A wykazuje charakterystykę opadającą - działa jak rzeczywiste źródło napięcia z rezystancją wewnętrzną $R_{w}=0,035 \Omega$ (wycinek obszaru zwarcia widoczny na rysunku 4), natomiast urządzenie $B$ charakterystykę stałoprądową - źródło prądu (wycinek obszaru zwarcia widoczny na rysunku 5).

Charakterystykę statyczną urządzenia A można opisać funkcjami:

$\left\{\mathrm{I}=I_{n}=\right.$ const $-\mathrm{w}$ zakresie pracy,

$U=U_{n}-R_{z} I-w$ stanie zwarcia.

Charakterystykę statyczną urządzenia B można opisać funkcjami:

$\left\{\mathrm{I}=I_{n}=\right.$ const $-\mathrm{w}$ zakresie pracy,

$\left\{\mathrm{I}=\mathrm{I}_{\mathrm{sw}}=\right.$ const $-\mathrm{w}$ stanie zwarcia.

Podsumowując, oba urządzenia działają jak źródła prądu w czasie pracy, różnica pojawia się podczas zwarcia. Urządzenie A pracuje wtedy jak źródło napięcia z wewnętrzną opornością, urządzenie B jak źródło prądu. Ze względu na ograniczoną liczbę dostępnych oporności obciążenia nie jest możliwe precyzyjne określenie, przy jakim obciążeniu następuje przełączenie pomiędzy zakresem pracy a zakresem zwarcia.

Odmienne cechy wykazuje urządzenie C w trybie spawania elektrodą otuloną, mające charakterystyki opadające ze zmieniającym się nachyleniem dla różnych nastaw (rys. 6). Przy niskiej wartości zadanego prądu obserwowane są niewielkie rozbieżności, które maleją dla wyższych nastaw. Charakterystyki te nie są liniowe, lecz zakrzywione: wklęsłe dla nastaw poniżej $120 \mathrm{~A}$, wypukłe dla nastaw powyżej $120 \mathrm{~A}$.

Urządzenie C w trybie spawania metodą MIG/ MAG wykazuje płaskie charakterystyki w zakresie roboczym określonym umownym napięciem spawania $U=15+0,05 I-$ utrzymuje stałe napięcie niezależnie od prądu (rys. 7).

Urządzenie D, transformator z prostownikiem diodowym, wykazuje charakterystyki płaskie, jednak „granicznie" stromo opadające. Jest to źródło napięcia o oporności wewnętrznej wynoszącej, dla poszczególnych nastaw, kolejno $\mathrm{R}_{\mathrm{w}}=0,079 ; 0,090 ; 0,103 \Omega$. Punkt zwarcia leży dokładnie na linii charakterystyki:

$$
U=U_{n}-R_{z} I
$$

\section{Podsumowanie}

Badania pokazały, że odpowiednio mierzone charakterystyki statyczne nadal mogą być źródłem informacji o właściwościach spawalniczych źródeł energii. Dotyczy to zarówno źródeł konwencjonalnych, jak
Można więc przypuszczać, że dla oporności obciążenia pomiędzy 0,1 a $0,0 \Omega$ także spełnia powyższą zależność (2).

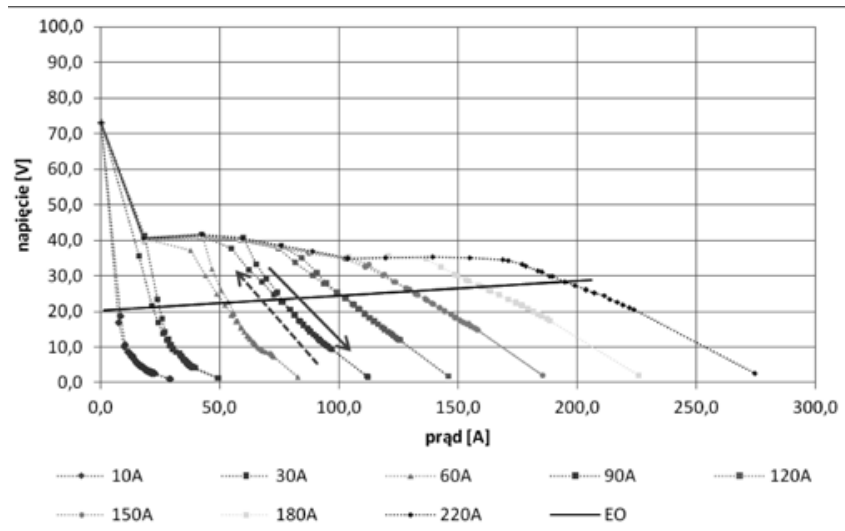

Rys. 6. Zbiór charakterystyk statycznych urządzenia C w trybie spawania elektrodą otuloną

Fig. 6. Static characteristics bunch of device $\mathrm{C}$ for MMA welding

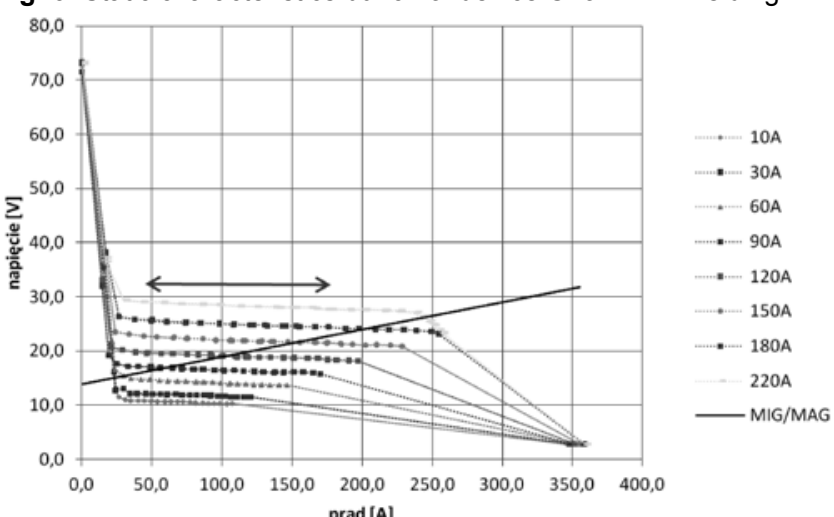

Rys. 7. Zbiór charakterystyk statycznych urządzenia $\mathrm{C} w$ trybie spawania metodą MIG/MAG

Fig. 7. Static characteristics bunch of device $C$ for MIG/MAG welding

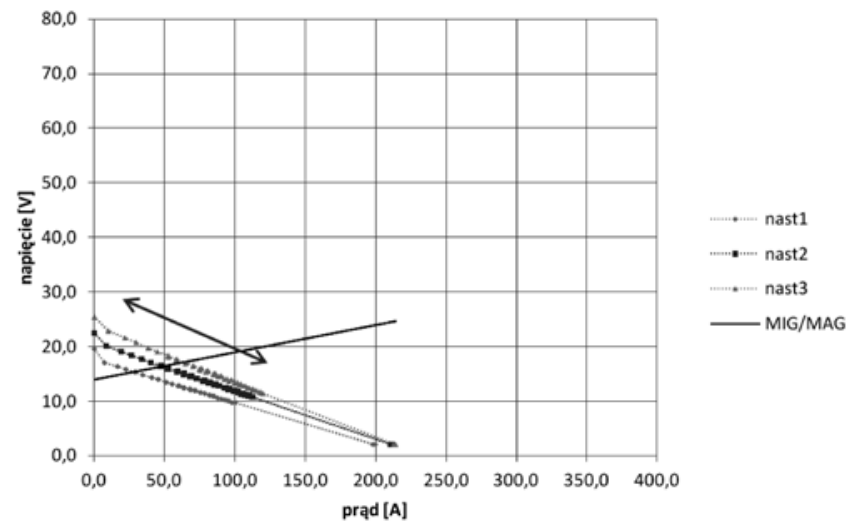

Rys. 8. Zbiór charakterystyk statycznych urządzenia D do spawania metodą MIG/MAG

Fig. 8. Static characteristics bunch of device D for MIG/MAG welding i nowoczesnych urządzeń inwertorowych. Prezentowane wyniki można było uzyskać dzięki nowatorskiej koncepcji zautomatyzowanego pomiaru ze sterowanym obciążeniem rezystancyjnym. 


\section{Literatura}

[1] Cegielski P., Kolasa A., Skrzyniecki K., Kołodziejczak P.: Komputerowy system do badań właściwości statycznych i dynamicznych źródeł energii elektrycznej do spawania łukowego. Przegląd Spawalnictwa 1/2012, s. 3-9.

[2] Kolasa A., Cegielski P., Skrzyniecki K.: Charakterystyki statyczne i dynamiczne układu źródło zasilania - łuk, dla różnych metod spawania. Spajanie 3/2011, s. 36-39.

[3] Pierożek B., Lassociński J.: Spawanie łukowe stali w osłonach gazowych, WNT Warszawa 1987.

[4] Projekt badawczy własny Ministra Nauki i Szkolnictwa Wyższego nr N N503 206339 pt. Badanie zależności pomiędzy zjawiskami zachodzącymi w łuku spawalniczym w różnych odmianach metody MAG a parametrami elektrycznymi układu łuk - urządzenie spawalnicze. Kierownik: prof. nzw. dr hab. inż. Andrzej Kolasa.

[5] Skrzyniecki K., Kolasa A., Cegielski P.: Badanie charakterystyk statycznych i dynamicznych układu źródło zasilania - łuk. Przegląd Spawalnictwa 6/2011, s. 33-36.

[6] Skrzyniecki K., Krajewski A., Cegielski P., Hudycz M., Kolasa A.: Zastosowanie wirtualnych przyrządów pomiarowych do badania urządzeń i procesów spawalniczych. Prace Naukowe Politechniki Warszawskiej, Mechanika, z. 229 „Innowacje w technikach spajania”, s. 115-124, Warszawa 2009.

\section{Dolnośląska Sekcja Spawalnicza SIMP \\ Zakład Spawalnictwa Instytutu Technologii Maszyn i Automatyzacji i Wydział Mechaniczny Politechniki Wrocławskiej}

\section{zapraszają do udziału \\ w 4. Międzynarodowej Konferencji Naukowo - Technicznej pod hasłem „POSTĘP W TECHNOLOGIACH LUTOWANIA” WROCKAW 2013}

\section{Wrocław, 23-25 września 2013 (poniedziałek - środa) aula A1, bud. B-4 PWr, ul. Łukasiewicza 5}

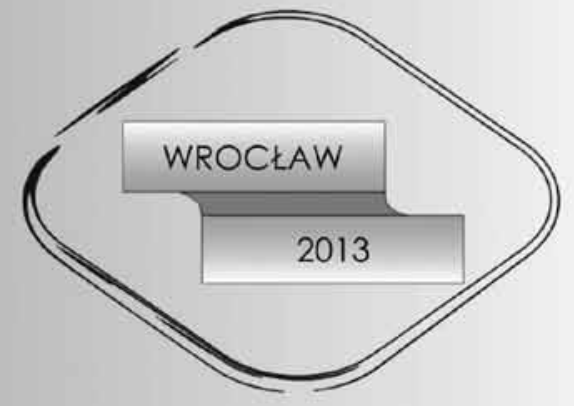

Wszystkich zainteresowanych udziałem w Konferencji prosimy o kontakt z Zakładem Spawalnictwa ITMiA Politechniki Wrocławskiej

Prof. dr hab. inż. dr h.c. Władysław Włosiński - Przewodniczący Komitetu Naukowego IV Wydzial Nauk Technicznych PAN Warszawa

Prof. dr hab. inż. Andrzej Ambroziak - Sekretarz Komitetu Naukowego tel. (071) 3202148, e-mail: andrzej.ambroziak@pwr.wroc.pl

Prof. dr hab. inż. Zbigniew Mirski - Przewodniczący Komitetu Organizacyjnego tel. (071) 3202142, e-mail: zbigniew.mirski@pwr.wroc.pl

Mgr inż. Anna Woźna - Sekretarz Komitetu Organizacyjnego tel. (071) 3202074, e-mail: anna.wozna@pwr.wroc.pl

Dr inż. Tomasz Piwowarczyk - Sekretarz Komitetu Organizacyjnego tel. (071) 3204255, e-mail: tomasz.piwowarczyk@pwr.wroc.pl

Korespondencję prosimy kierować na adres: Komitet Organizacyjny 4. Międzynarodowej Konferencji Naukowo - Technicznej „Postęp w technologiach lutowania” Politechnika Wrocławska, Zakład Spawalnictwa ITMiA Wybrzeże Wyspiańskiego 27

\section{0-370 Wrocław}

